\title{
Sulama Suyu Kalitesi Açısından Çanakkale-Biga Ovası Yeraltı Sularının Durumu
}

\author{
Emre Topçu $^{1^{*}} \quad$ İsmail Taş $^{2}$ \\ ${ }^{1}$ Isparta Uygulamalı Bilimler Üni. Ziraat Fak. Tarımsal Yapılar ve Sulama Bölümü, Isparta. \\ ${ }^{2}$ Çanakkale Onsekiz Mart Üni. Ziraat Fak. Tarımsal Yapılar ve Sulama Bölümü, Çanakkale. \\ *Sorumlu yazar: emretopcu@isparta.edu.tr \\ ${ }^{1}$ https://orcid.org/0000-0001-6521-5481, ${ }^{2}$ https://orcid.org/0000-0002-4419-747X
}

Geliş tarihi:05.05.2020

Kabul tarihi:10.07.2020

$\ddot{\mathbf{O z}}$

$\mathrm{Su}$, canlı yaşamının en önemli gereksinimidir. Yeraltı suları özellikle kurak dönemlerde en önemli su kaynağıdır. Söz konusu kaynak, halihazırda özellikle hatalı ve özensiz kullanımlar nedeniyle kirlenerek kullanılamaz hale gelmektedir. Biga Ovası, Çanakkale ilinin en büyük ovası olup tarımsal üretimin yoğun olarak yapıldığı bölgelerdendir. Çalışma alanında 20 kuyudan alınan su örneklerinde; Elektriksel iletkenlik (EC), pH, Potasyum (K), Kalsiyum (Ca), Magnezyum (Mg), Sodyum (Na), Karbonat $\left(\mathrm{CO}_{3}\right)$, Bikarbonat $\left(\mathrm{HCO}_{3}\right)$, $\mathrm{Klorür}$ $(\mathrm{Cl})$, Sülfat $\left(\mathrm{SO}_{4}\right)$, Nitrat $\left(\mathrm{NO}_{3}\right)$ ve Bor $(\mathrm{B})$ parametreleri incelenmiştir. Su Kirliliği Kontrolü Yönetmeliği (SKKY) Sınıflandırma Sistemi dikkate alınarak sınıflandırıldığında ve tuzluluk parametresi dikkate alındığında 20 kuyudan 11'i ikinci sınıf diğerleri ise birinci sınıf olarak belirlenmiștir. Koruoba 1 ve Örtülüce 5 kuyuları civarındaki yeraltı sularının EC'leri yüksek bulunmuştur. Geçirgenlik parametresi bakımından ise 12 kuyu ikinci sınıf olarak tespit edilmiştir. Özel iyon toksisitesi açsından sodyum için 7 kuyu üçüncü sınıf, bor bakımından da sadece Yeniçiftlik DSİ kuyusu üçüncü sınıf olarak tespit edilmiştir. Yeraltı sularında nitrat kirliliği dışında, çalışma alanı genelinde mevcut durumda belirgin bir problemin henüz oluşmadığı belirlenmiştir.

Anahtar Kelimeler: Su kirliliği, Sınıflandırma, Kuyu suyu

\section{Irrigation Water Quality for Groundwater of Çanakkale-Biga Plain \\ Abstract}

Water is the essential component of life. Groundwater is the most important water resource especially during the dry periods. Groundwater resources are polluted and become unusable especially due to careless misuses. Biga Plain is the largest plain of Çanakkale province where agricultural practices are widely carried out. In this study, water samples were taken from 20 groundwater wells and samples were subjected to; Electrical conductivity (EC), pH, Potassium (K), Calcium (Ca), Magnesium $(\mathrm{Mg})$, Sodium $(\mathrm{Na})$, Carbonate $\left(\mathrm{CO}_{3}\right)$, Bicarbonate $\left(\mathrm{HCO}_{3}\right)$, Chloride $(\mathrm{Cl})$, Sulfate $\left(\mathrm{SO}_{4}\right)$, Nitrate $\left(\mathrm{NO}_{3}\right)$ and Boron $(\mathrm{B})$ analyses. When the Water Pollution Control Regulation Classification System was taken into consideration (WPCR), 11 of 20 wells were classified as the second-class and the others as the first-class in terms of salinity parameter. Salinity parameters were slightly high around Koruoba and Örtülüce wells. In terms of permeability parameter, 12 wells were determined as the second-class. In terms of specific ion toxicity, 7 wells were found to be the third-class for sodium and only Yeniçiftlik DSİ well was found to be the third-class for boron. A remarkable pollution was not identified in the region, except for nitrate pollution.

Keywords: Water pollution, Classification, Well water

\section{Giriş}

Günümüzde nüfus artışı başta olmak üzere tarımsal, kentsel, sanayi ve turizm alanlarındaki büyümeler sulama, içme, rekreasyon ve sanayi sektörlerinde su ihtiyaçlarının hızlı bir şekilde artmasına sebep olmaktadır. Artan su ihtiyaçları ise yüzey ve özellikle yeraltı su kaynakları (YAS) üzerinde önemli kullanım baskılarına neden olmaktadır. Sulama suyu özellikleri, temin edildiği kaynağa, iklime ve jeolojik yapıya göre farklılıklar göstermektedir. Sulama suyu kaynağının yerüstü veya yeraltı kaynağı olması suyun niteliğini önemli ölçüde etkilemektedir. Sulamada kullanılan suyun kalitesi sadece toprağı etkilemekle kalmayıp, kullanılan gübre ve ilaçların etki mekanizmalarını, sulama sistemlerinde kullanılan metal bölümleri, damlatıcı ve yağmurlama başlıklarının tıkanması gibi olumsuzluklar gösterebilmektedir (Taş ve Davarc1, 2017). 
Amerika Birleşik Devletleri Çevre Koruma Örgütüne (EPA) göre su kirliliğin tanımı, su kalitesini ölçülebilecek düzeyde kötüleştiren oranda ya da konsantrasyonda zararlı veya istenmeyen maddelerin ilave edilmesidir (Taş ve ark., 2013). Yüzey kaynaklarının kirletilmesi hızlı ve kolay olabilirken, yeraltı su kaynaklarının kirletilmesi genellikle yavaş ve güç olabilmektedir. Noktasal ve noktasal olmayan kaynaklardan yer altına sızan kirletici maddeler, yeraltı sularını geri dönüşümü oldukça zor olacak şekilde kirletmekte, giderilmesi yüksek maliyetler ve aynı zamanda uzun zaman gerektiren kirlilik problemi ile karşı karşıya bırakmaktadır (Zaporozec ve Miller, 2000).

Katkat ve Özgüven (2000), Biga'da domates üretiminde kullanılan yeraltı sularının anyon ve katyonlarını incelemişlerdir. Üretim alanından toplanan 18 adet toprak ve 11 adet de su örneğinde yapılan analizler sonucunda üretim yapılan topraklarda tuzluluk sorunun olmadığı ve sulama suların $\mathrm{pH}$ değerinin ise 8'e yakın olduğunu belirlemişlerdir.

Kavurmacı ve ark. (2010), Aksaray ovası yeraltı su kalitesinin belirlenmesine yönelik yapılan çalışma kapsamında 3 kaynak, 37 kuyu olmak üzere toplam 40 noktadan örnekleme yapmışlardır. Ağustos 2007'den Haziran 2008'e kadar toplanan örneklerde fizikokimyasal parametreler analiz edilmiş ve CBS'den faydalanarak alanının su kalitesi haritaları hazırlanmıştır. Ova sularının düşük sodyum içeriğine sahip ancak orta derecede tuzluluk gösterdiği belirlenmiştir. Tuz Gölü'nün güney ve güneydoğu bölgelerinde yeraltı sularında tuzluluğun artış gösterdiği ve söz konusu bölgedeki akiferlere tuzlu su girişi olduğunu bildirmişlerdir.

Yeraltı suları bir kez kirlendiğinde temizlenmesi çok güç ve pahalı olmaktadır. Temizliğin başarısında en önemli iki faktör uygun teknoloji kullanmak ve sorumluluktur. YAS'daki kirleticilerin izlenmesi hızlı olursa kirleticinin taşınmış olduğu mesafe kısa olur ve kirleticilerin temizlenmesi böylelikle başarıya ulaşabilir. Uygun bir temizleme teknolojisinin seçimi ve tasarımı; yerin hidrojeolojisine, kirlilik kaynaklarının tip, konsantrasyon ve dağılımına, YAS'ın yenilenme potansiyeline bağlıdır (Zaporozec ve Miller, 2000). YAS kirliliğinin izlenmesi ve değerlendirilmesi, yönetimsel tedbirlerin alınması bakımından da gereklidir (Angle ve Baker, 2001). YAS kaynaklarının korunması, ancak etkili bir yönetim anlayışı ile sağlanabilir. Etkili bir yönetim için, mevcut faaliyetlerin YAS kaynaklarına olan etkisinin saptanması ve uygulanacak olan planların etkilerinin kestirilmesi gerekir.

Bu çalışmada Çanakkale ili Biga ilçesi sınırlarında kalan ağırlıklı olarak Biga Ovasını temsil edecek şekilde 20 adet yeraltı kuyusundan alınan su örnekleri, kalitelerini belirlemek amacıyla analiz edilerek mevcut kaliteleri belirlenmiş ve Su Kalitesi Kontrol Yönetmenliği kriterlerine göre sınıflandırılmıştır.

\section{Materyal ve Yöntem \\ Çalışma alanı}

Araştırma alanı Çanakkale ilinin en büyük yüzölçümüne sahip Biga ilçesidir (Şekil 1). İlçenin yüzölçümü $1331 \mathrm{~km}^{2}$ 'dir. İlçenin en batısında $26^{\circ} 53^{\prime} 15^{\prime \prime}$ doğu boylamı, en doğusunda $27^{\circ} 31^{\prime} 00^{\prime \prime}$ doğu boylamı, en güneyinde $40^{\circ} 05^{\prime} 30^{\prime \prime}$ kuzey enlemi, en kuzeyinde ise $40^{\circ} 28^{\prime} 30^{\prime \prime}$ kuzey enlemi geçmektedir (Anonim, 2016a). İlçede 134075 ha'lık alanın \%44,21'i işlemeli tarıma uygun, \%55,79'u işlemeli tarıma uygun değildir. İlçenin \%39,53'ü orman arazisi olup, en yaygın toprak tipi 43901 ha ile Kireçsiz Kahverengi Orman Topraklarıdır. Toplam arazi varlığının 79214 ha'ı $(\% 74,18)$ orta, dik, çok dik ve sarp arazilerden oluşmaktadır. Arazilerin \%33,87'sinde taşlık ve kayalık, \%10,7'inde yaşlık ve çoraklık görülmektedir. Biga, Çanakkale ilinin tarımsal açıdan en önemli ilçesi olduğunu yaklaşık 73187 ha tarım arazisi varlığ ile kanıtlamaktadır. Yaklaşık 3015 ha $(\% 4,1)$ sulanabilir, 10042 ha'1 $(\% 13,7)$ ise sınırlı sulanabilir özelliktedir. Biga ilçesinde yaklaşık 35000 ha'lık alanı kaplayan 1. ve 2. derecede önemli tarım alanları sırasıyla; Alüviyal, Vertisol, Kırmızısımsı Kahverengi Akdeniz, Kireçsiz Kahverengi Orman ve Kolüviyal Büyük Toprak Gruplarına ait çeşitli haritalama birimleri içerisinde yer almaktadır (Ekinci ve ark., 2008). 


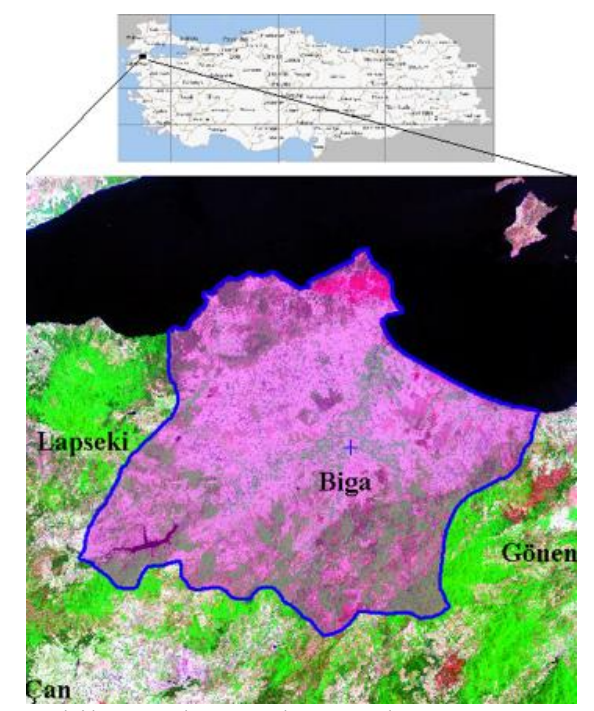

Şekil 1: Çalışma alanının konumu.

Biga'da 8 ile $81 \mathrm{~m}$ arasında kalınlığa sahip alüvyon bulunmaktadır. Gümüşçay, Kaldırımbaşı, Çakirbey ve Çavuşköy civarında yaklaşı $175 \mathrm{~km}^{2}$ ’lik alanda kalınlık en fazladır. Anılan kalın kil tabaka arasında değişik çaplarda çakıl ve kum bulunması nedeniyle geçirgen olup siltli kumlu çakı1lı alanlarda da yarı geçirgen bir yapı sergilemektedir. Bölgede açılan kuyuların 14,4 - 31 lt/sn aralığında verdisi, 42 - 100 m derinliği ve 11,99-31,87 m'de dinamik seviyesi bulunmaktadır (Doğukan ve ark., 2007).

Çalışma alanında yoğun şekilde tarımsal üretim (ekmeklik ve makarnalık buğday, arpa, mısır, yonca, fĭğ, korunga v.b.) yapılmaktadır. Sulama suyu kısıtına bağlı olarak özellikle çeltik üretimi bölgede hakim bitki deseni olarak ortaya çıkmaktadır.

\section{İklim Özellikleri}

Çalışma alanında Akdeniz ve Karadeniz geçiş iklimi özelliği görülmektedir. Çalışma alanına ait uzun yıllık iklim verileri Çizelge 1'de verilmiştir. Uzun yıllık gözlem sonuçlarına göre en yağışlı ay Ocak, en kurak ay ise Ağustos ayıdır. Ortalama yıllık yağış toplamı 691,3 mm'dir (Anonim, 2016b).

Çizelge 1. Çalışma alanına ait uzun yıllık iklim verileri.

\begin{tabular}{|c|c|c|c|c|c|c|c|c|c|c|}
\hline Aylar & $\begin{array}{l}\text { Tort } \\
\left({ }^{\circ} \mathrm{C}\right)\end{array}$ & $\begin{array}{c}\text { Tmax } \\
\left({ }^{\circ} \mathrm{C}\right)\end{array}$ & $\begin{array}{l}\text { Tmin } \\
\left({ }^{\circ} \mathrm{C}\right)\end{array}$ & $\begin{array}{c}\text { Ort. } \\
\text { Buhar } \\
\text { Basinc1 } \\
(\mathrm{hPa})\end{array}$ & $\begin{array}{l}\text { Ort. } \\
\text { Nem } \\
(\%)\end{array}$ & $\begin{array}{l}\text { Toplam } \\
\text { Yağı̧̧ } \\
\text { Ort. } \\
(\mathrm{mm})\end{array}$ & $\begin{array}{c}\text { Ort. } \\
\text { Rüzgar } \\
\text { Hizı } \\
(\mathrm{m} / \mathrm{s})\end{array}$ & $\begin{array}{c}\text { Kar } \\
\text { Yağışlı } \\
\text { Günler } \\
\text { Sayısı }\end{array}$ & $\begin{array}{c}\text { Kar } \\
\text { Örtülü } \\
\text { Günler } \\
\text { Say1S1 }\end{array}$ & $\begin{array}{l}\text { Maks. } \\
\text { Kar } \\
\text { Kalınlığ } \\
\text { (cm) }\end{array}$ \\
\hline Ocak & 5,4 & 9,5 & 2,1 & 7,0 & 76,5 & 98,9 & 1,8 & 3,2 & 1,9 & 41 \\
\hline Şubat & 5,8 & 10,3 & 2,3 & 6,9 & 73,5 & 69,9 & 1,9 & 3,6 & 1,6 & 29 \\
\hline Mart & 7,8 & 12,7 & 3,8 & 7,7 & 72,8 & 72,5 & 1,7 & 1,5 & 0,4 & 32 \\
\hline Nisan & 12,6 & 18,5 & 7,5 & 9,9 & 68,8 & 59,0 & 1,4 & 0,1 & & \\
\hline Mayıs & 17,0 & 23,1 & 11,4 & 13,0 & 67,4 & 40,5 & 1,2 & 0,1 & & \\
\hline Haziran & 21,4 & 28,0 & 14,7 & 15,8 & 62,4 & 31,5 & 1,3 & & & \\
\hline Temmuz & 23,3 & 29,4 & 16,8 & 17,3 & 61,1 & 18,0 & 1,6 & & & \\
\hline Ağustos & 22,9 & 29,0 & 16,9 & 17,4 & 63,0 & 14,4 & 1,7 & & & \\
\hline Eylül & 19,4 & 26,2 & 13,9 & 14,8 & 66,2 & 32,2 & 1,5 & & & \\
\hline Ekim & 14,9 & 21,0 & 10,6 & 12,2 & 71,8 & 69,8 & 1,5 & & & \\
\hline Kasım & 10,5 & 15,8 & 6,7 & 9,8 & 75,4 & 87,1 & 1,3 & 0,2 & & \\
\hline Aralık & 7,3 & 11,6 & 3,9 & 7,9 & 75,9 & 97,5 & 1,5 & 1,2 & 0,5 & 37 \\
\hline $\begin{array}{l}\text { Ort. / } \\
\text { Top. }\end{array}$ & 14,0 & 19,6 & 9,2 & 11,6 & 69,6 & 691,3 & 1,5 & 9,9 & 4,4 & 34,8 \\
\hline
\end{tabular}




\section{Örnekleme noktaları}

Örnekleme işlemi sırasında, yeraltı suyu kullanılan bölgeler içerisinde çalışma alanını en iyi temsil edecek şekilde örnekleme yapılmıştır (Şekil 2). Bu kapsamda Ağaköy 1, Balıklıçeşme 2, İdriskoru 1, Kocagür 2, Koruoba 2, Kozçeşme 2, Örtülüce 7, Pekmezli 1 ve Yeniçiftlik 2 adet olmak üzere toplam 20 kuyuda örnekleme yapılmıştır.

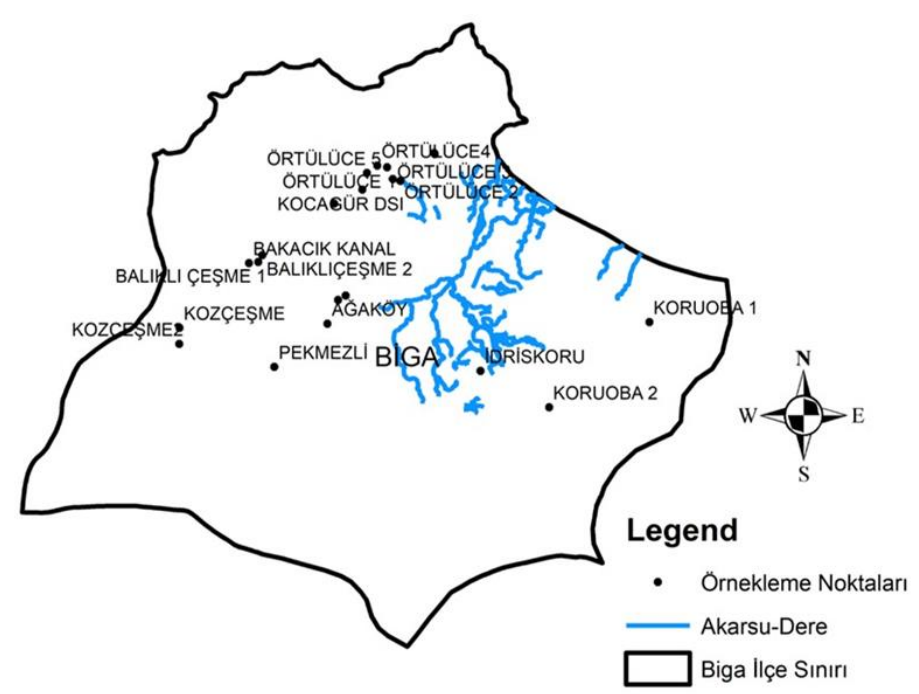

Şekil 2. Çalışma alanı ve örnekleme noktaları

\section{Su analiz yöntemleri}

Çalışma sahasından usulüne uygun olarak toplanan su numuneleri, Çanakkale Onsekiz Mart Üniversitesi Bilim ve Teknoloji Uygulama ve Araştırma Merkez Laboratuvarlarının ilgili bölümünde Çizelge 2'de verilen yöntemler kullanılarak analiz edilmiştir.

Çizelge 2. Su örneklerinin analiz yöntemleri.

\begin{tabular}{lcc}
\hline Yapılacak analizin adi & Birimi & Yöntemi \\
\hline Elektriksel iletkenlik & micromhos/cm & Kondüktivimetre \\
$\mathrm{pH}$ & & $\mathrm{pH}$ metre \\
Potasyum & $\mathrm{ppm}$ & ICP-OES \\
Kalsiyum & $\mathrm{ppm}$ & ICP-OES \\
Magnezyum & $\mathrm{ppm}$ & ICP-OES \\
Sodyum & $\mathrm{ppm}$ & ICP-OES \\
Karbonat ve Bikarbonat & $\mathrm{me} / \mathrm{lt}$ & $\mathrm{H}_{2} \mathrm{SO}_{4}$ ile titrasyon \\
Klorür & $\mathrm{ppm}$ & İon Kromotografisi \\
Sülfat & $\mathrm{ppm}$ & İyon Kromatografisi \\
Nitrat & $\mathrm{ppm}$ & ICP-OES \\
Bor & $\mathrm{ppm}$ & ICP-OES \\
\hline
\end{tabular}

\section{Bulgular ve Tartışma}

\section{Katyon ve anyon içeriğindeki değişimi}

Örnekleme yapılan kuyuların katyon ( $\mathrm{Na}, \mathrm{Ca}$ ve $\mathrm{Mg}$ ) analiz sonuçları grafik halinde Şekil 3'de sunulmuştur. Su Kirliliği Kontrolü Yönetmeliği Kıtaiçi Su Kaynaklarının Sınıflarına Göre Kalite Kriterleri Tablosu göz önüne alındığında, söz konusu kuyularda Na bakımından Ağaköy $(1,79$ me/l), Kocagür DSİ (1,61 me/l), Kocagür Yeni (2,24 me/l), Koruoba 2 (0,64 me/l), Kozçeşme (2,84 me/l), Kozçeşme 2 (2,41 me/l), Örtülüce $1(1,95 \mathrm{me} / \mathrm{l})$, Örtülüce $2(2,49 \mathrm{me} / \mathrm{l})$, Örtülüce $4(1,26 \mathrm{me} / \mathrm{l})$, Örtülüce 6 (2,31 me/l), Örtülüce 7 (1,21 me/l) ve Yeni Çiftlik DSİ (1,93 me/l) 1. Sinıfa dahil olmuştur. 
Balıklıçeşme 1 (5,19 me/l), Balıklıçeşme 2 (4,42 me/l), İdriskoru (5,23 me/l), Koruoba 1 (5,59 me/l), Örtülüce 3 (3,28 me/l), Örtülüce 5 (6,42 me/l), Pekmezli (4,39 me/l), Yeniçiftlik Yeni Kuyu $(4,81$ me/l) 2. Sinıfta yer almıştır.

Örnekleme kuyularında Ca bakımından en düşük değerin Yeni Çiftlik Yeni Kuyuda $(0,30$ me/l), en yüksek değerin ise Örtülüce 3 'de $(5,01 \mathrm{me} / \mathrm{l})$ olduğu gözlemlenmiştir. Kuyuların $\mathrm{Mg}$ içerikleri incelendiğinde en düşük değer Yeni Çiftlik Yeni Kuyuda $(0,09$ me/l) ve en yüksek değer ise Örtülüce 5'de (6,54 me/l) tespit edilmiştir.

Analiz sonuçlarına göre anyon değerleri Şekil 4'te grafik halinde sunulmuştur. Buna göre; en düşük $\mathrm{HCO}_{3}$ miktarı Koruoba 2'de $(0,20)$, en yüksek $\mathrm{HCO}_{3}$ miktarı Örtülüce 1'de $(4,00)$ tespit edilmiştir. SKKY sulama sularının sınıflandırılmasında esas alınan sulama suyu kalite parametrelerine göre Cl bakımından, Ağaköy (1,46 me/l), Kocagür DSİ (2,38 me/l), Kocagür Yeni $(1,91 \mathrm{me} / \mathrm{l})$, Koruoba $2(0,81 \mathrm{me} / \mathrm{l})$, Kozçeşme $(1,71 \mathrm{me} / \mathrm{l})$, Kozçeşme $2(0,89 \mathrm{me} / \mathrm{l})$, Örtülüce $1(0,08 \mathrm{me} / \mathrm{l})$ Örtülüce $2(3,12 \mathrm{me} / \mathrm{l})$, Örtülüce $4(1,25 \mathrm{me} / \mathrm{l})$, Örtülüce $6(2,64 \mathrm{me} / \mathrm{l})$, Örtülüce $7(1,61 \mathrm{me} / \mathrm{l})$, Pekmezli (3,32 me/l), Yeni Çiftlik Yeni kuyu (1,67 me/l), Yeni Çiftlik DSİ (2,19 me/l) 1 . sinıfta yer almıştır.

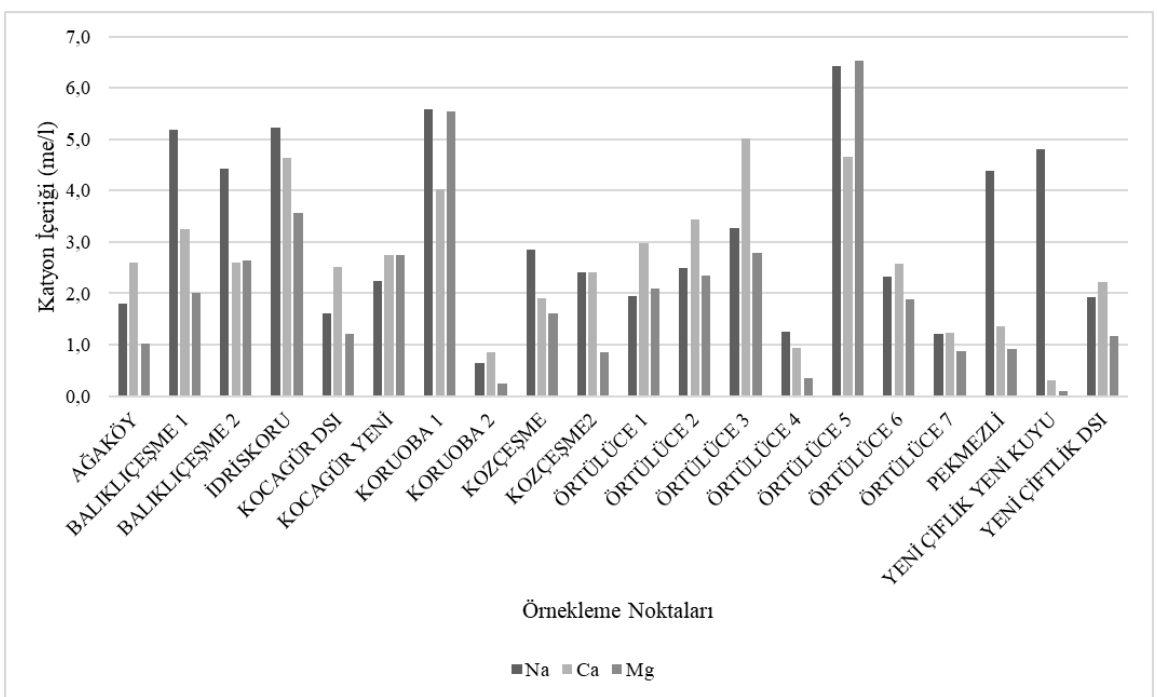

Şekil 3. Kuyuların katyon değerlerindeki değişim.

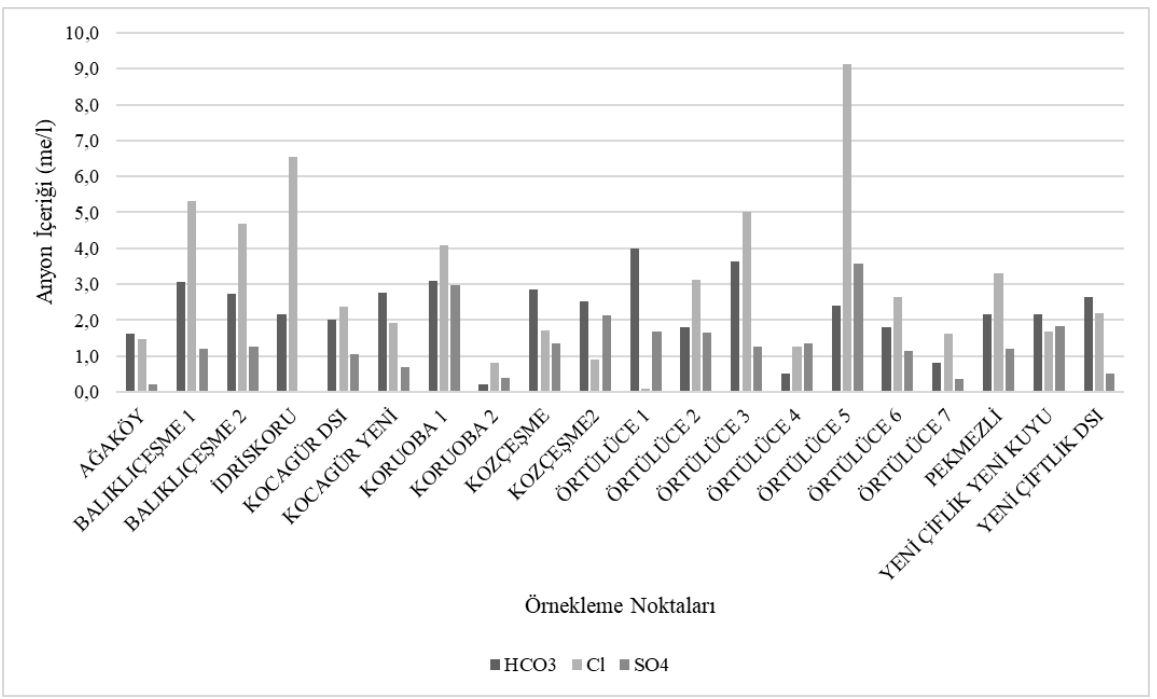

Şekil 4. Kuyuların anyon değerlerindeki değişim.

Balıklıçeşme 1 (5,32 me/l), Balıklıçeşme 2 (4,68 me/l), İdriskoru (6,54 me/l), Koruoba 1 (4,07 me/l), Örtülüce $3(5,01 \mathrm{me} / \mathrm{l}) 2$ 2. sinıfa dahil olmuştur. Örtülüce 5 3. sinıfta yer almıştır. $\mathrm{SO}_{4}$ bakımından tüm kuyular 0-3,57 me/l arasında değişmektedir ve 1 . sınıfa dahil olmuşlardır. 


\section{EC, pH ve SAR değerlerindeki değişim}

Kuyu sularının EC değerleri 0,209 - 1,818 dS/m arasında değişim sergilemiştir (Şekil 5). Örnekleme kuyularından, Koruoba $2(0,209 \mathrm{dS} / \mathrm{m})$, Örtülüce $4(0,312 \mathrm{dS} / \mathrm{m})$, Örtülüce $6(0,686 \mathrm{dS} / \mathrm{m})$, Örtülüce $7(0,352 \mathrm{dS} / \mathrm{m})$, Ağaköy $(0,552 \mathrm{dS} / \mathrm{m})$, Kocagür DSİ $(0,599 \mathrm{dS} / \mathrm{m})$, Yeni Çiftlik Yeni Kuyu $(0,6 \mathrm{dS} / \mathrm{m})$, Kozçeşme $2(0,62 \mathrm{dS} / \mathrm{m})$ ve Yeniçiftlik DSİ $(0,629 \mathrm{dS} / \mathrm{m}), 1$. sinıfa dahil olmuştur. 20 kuyudan 11'i ise EC bakımından 2. sınıfta yer almıştır.

SAR değerleri SKKY sulama sularının sınıflandırılmasında esas alınan sulama suyu kalite parametrelerine göre değerlendirildiğinde Yeni Çiftlik Yeni Kuyu haricinde tüm kuyular 1. sınıfa dahil olmuştur (Şekil 6). Kuyu sularının SAR değerleri 0,87-10,73 arasında değişmektedir. Yeni Çiftlik Yeni Kuyu 10,73 değeri ile SAR bakımından 2. sınıfta yer almaktadır.

Şekil 7'de görülebileceği gibi örnekleme yapılan kuyuların pH değerleri izin verilen sınırlar içerisinde kalmaktadır. Yeni Çiftlik DSİ kuyusu 6,92 pH değeri ile en düşük değere sahipken, yine Yeni Çiftlikteki Yeni Kuyu 8,30 pH değeri ile en yüksek değere sahiptir.

Arslan ve ark. (2007) yaptıkları çalışmada benzer bulgulara rastlamışlardır. Çalışmada 9 nolu kuyuya ait su C3S1 (Yüksek tuzlu-Düşük sodyumlu su) olup drenaj1 bulunmayan alanlarda kullanılmas1 sakıncalıdır, birinci ve 8. kuyulara ait sular C3S2(Yüksektuzlu-Orta sodyumlu su) olup bu suların drenajı bulunmayan alanlarda kullanılması sakıncalıdır. Dört nolu kuyunun sınıfı ise C4S2 (çok yüksek tuzlu-orta sodyumlu su), 5 nolu kuyunun sınıfı C4S3 (çok yüksek tuzlu-Yüksek sodyumlu su), 2, 3, 6, 7 ve 10 numaralı kuyuların sınıfı ise C4 S4'dir (çok yüksek tuzlu-Çok yüksek sodyumlu sular). Bu sınıf suların toprakların fazla geçirgen olmadığ yıkamanın olmadığı alanlarda kullanılması sakıncalıdır.

Yıldıztekin ve Tuna'nın (2011) Muğla Karabağlar yöresinde yapmış olduğu çalışmada ortalama pH değeri 6,54 bulunmuş ve sulama yönünden sorun yaratmadığı belirtilmiştir. Yine aynı çalışmada ortalama EC değeri $0,806 \mathrm{dS} / \mathrm{m}$ ölçülmüş ve özellikle yaz aylarında EC değerlerine dikkat etmek gerektiğini bildirmişlerdir.

Bozdağ (2017) Çumra Ovası'nda yapmış olduğu çalışmada 60 adet yeraltı suyu örneğinde kimyasal analizler yapmıştır. Yeraltı sularında $\mathrm{Ca}^{+2}$ ve $\mathrm{Mg}^{+2}$ hâkim katyonları oluştururken anyonlardan beslenim bölgesinden boşalım bölgesine doğru sırasıyla, $\mathrm{HCO}_{3}, \mathrm{HCO}_{3}-\mathrm{SO}_{4}, \mathrm{SO}_{4}-\mathrm{HCO}_{3}$ ve $\mathrm{SO}_{4}-\mathrm{Cl}$ fasiyeslerine geçiş gözlemlemiştir. Sulama suyu olarak yeraltı suyunun uygunluğunu belirlemek amacıyla elektriksel iletkenlik, sodyum adsorbsiyon oranı, sodyum yüzdesi, artıksal sodyum karbonat, geçirgenlik indeksi, magnezyum oran1, kelley indeksi parametreleri ve ABD tuzluluk laboratuvarı ve Wilcox diyagramı kullanmıştır. Ayrıca kalite değerlendirmesi için yeraltı sularına ait ağır metal ve toksik element konsantrasyonları ile azot türevleri kullanmıştır. Elde edilen verilere göre inceleme alanının doğusundaki Üçhüyükler, Ovakavağı ve Karkın çevresinde Geç Pliyosen-Kuvaterner akiferinin tarımsal aktiviteler ve diğer antropojenik etkenlerden daha fazla etkilendiği ve sulama suyu olarak kullanıma uygun olmadığını tespit etmiştir.

Yener ve Ongun (2017) yaptıkları çalışmada Sarıöl Ovası'nda sulama amaçlı kullanılan yer altı su kaynaklarının kalitesinin belirlenmesini amaçlamışlardır. Bu amaçla, 2014 yılı Nisan ve Eylül aylarında 26 kuyudan su örnekleri almışlar; elektriksel iletkenlik (EC), $\mathrm{pH}, \mathrm{Na}, \mathrm{K}, \mathrm{Ca}^{+}, \mathrm{Mg}, \mathrm{Cl}, \mathrm{CO}_{3}$, $\mathrm{HCO}_{3}, \mathrm{SO}_{4}, \mathrm{NO}_{3}$ ve $\mathrm{B}$ analizleri yapmışlardır. Bunun yanında, sodyum adsorbsiyon oranı (SAR), sulama suyu sınıfı ve kalıcı sodyum karbonat (RSC) değerlerini de belirlemişlerdir. Su örneklerinde $(\mathrm{n}=52)$ pH'nın $6.70-7.50$ ve elektriksel iletkenliğin $562-1323 \mu \mathrm{S} \mathrm{cm}^{-1}$ aralığında değiştiği saptamışlardır. Tuzluluk sınıfının C2-C3 arasında değiştiği, alkalilik sınıfının $\mathrm{S}_{1}$ olduğu ve herhangi bir özel iyon etkisinin olmadığı belirlemişlerdir. Bölge sularında $\mathrm{NO}_{3}$ kirliliği bulunmamıştır. Çalışmada su örneklerinin $\mathrm{pH}$ ve EC değerleri jeoistatistiksel yöntemlerle de değerlendirmişlerdir. $\mathrm{pH}$ için etki aralığı (Ao) birinci ve ikinci örnekleme dönemi için sırasılyla 7200 ve $2312 \mathrm{~m}$ belirlenirken, EC için bu değer her iki dönem için de $7824 \mathrm{~m}$ olarak tespit etmişlerdir.

Demir ve Demir (2019) Harran ovasının güneydoğusunda Ohali köyünde faaliyette olan 13 adet yeraltı sulama suyu kaynağının, bazı kalite özellikleri ile sulama açısından öneminin belirlenmesi amacıyla çalışma yürütmüşlerdir. Analiz sonuçlarına göre su örneklerinin elektriksel iletkenlik değerini $1127-4090 \mu \mathrm{S} / \mathrm{cm}$ arasında belirlemişlerdir. Sulama sularının SAR değerlerini $1.05-3.41$ arasında, \%Na değerini ise \%16.2 - \%31.8 arasında bulmuşlardır. Dört farklı sınıflandırma sistemine göre değerlendirme yapmışlar ve genel olarak $6,7,8$ ve 9 nolu suları bütün sınıflandırma sisteminde en kötü sular olarak belirlemişlerdir. $\mathrm{Bu}$ suları sulama suyu olarak "uygun değill" olarak 
nitelendirmişlerdir. Bölgede pamuk ve mısır gibi bitki su tüketimi yüksek olan bitkilerin tarımının yapıldığını belirtmişlerdir ve gerekli önlemlerin alınmadığı taktirde toprakta tuzluluğun artacağını ve verim kayıplarının çok fazla olacağını belirtmişlerdir. Bunlarla birlikte bölgede uygun bir drenaj sisteminin tesis edilmesi gerektiğini önermişlerdir.

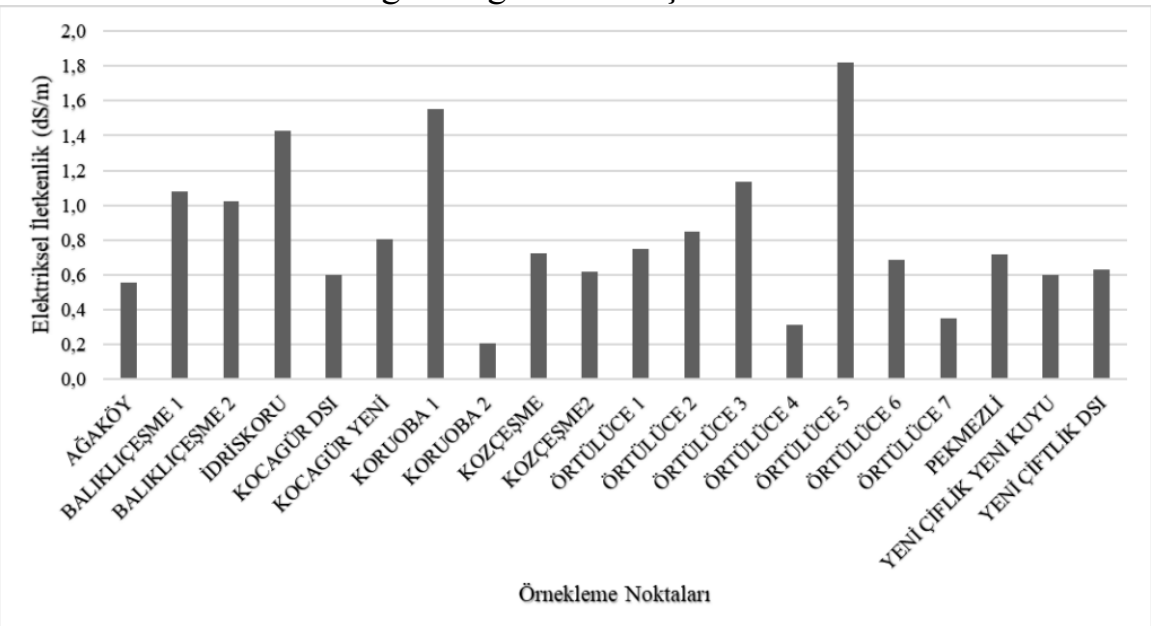

Şekil 5. Kuyuların EC değerlerindeki değişim.

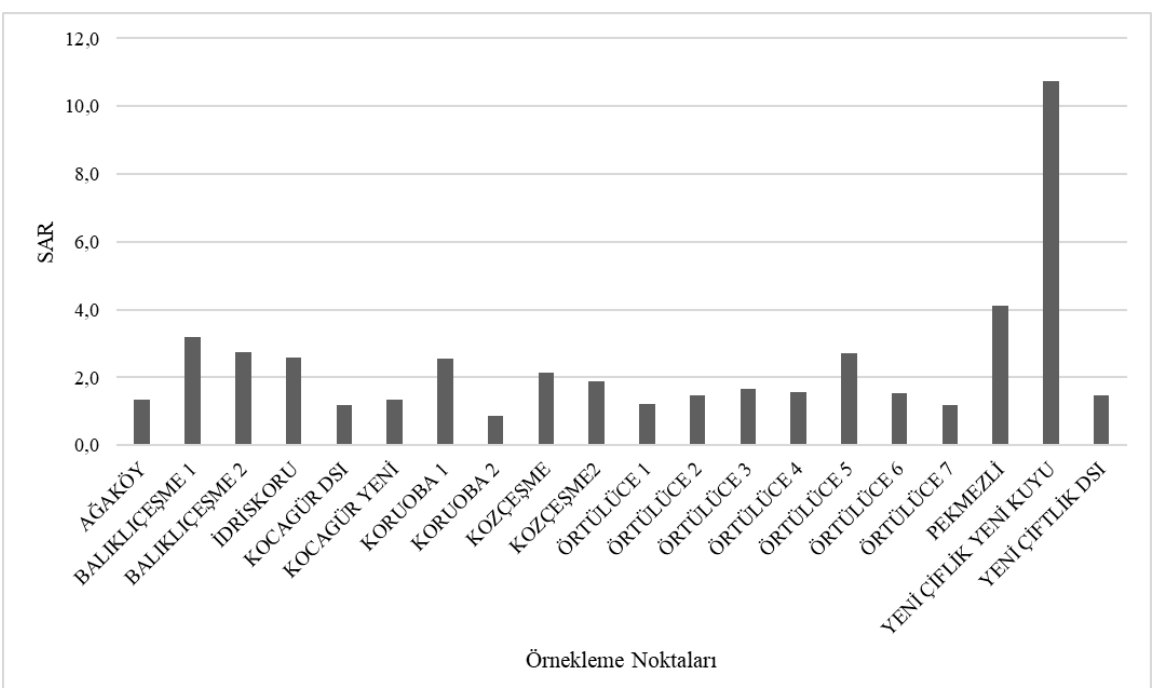

Şekil 6. Kuyuların SAR değerlerindeki değişim.

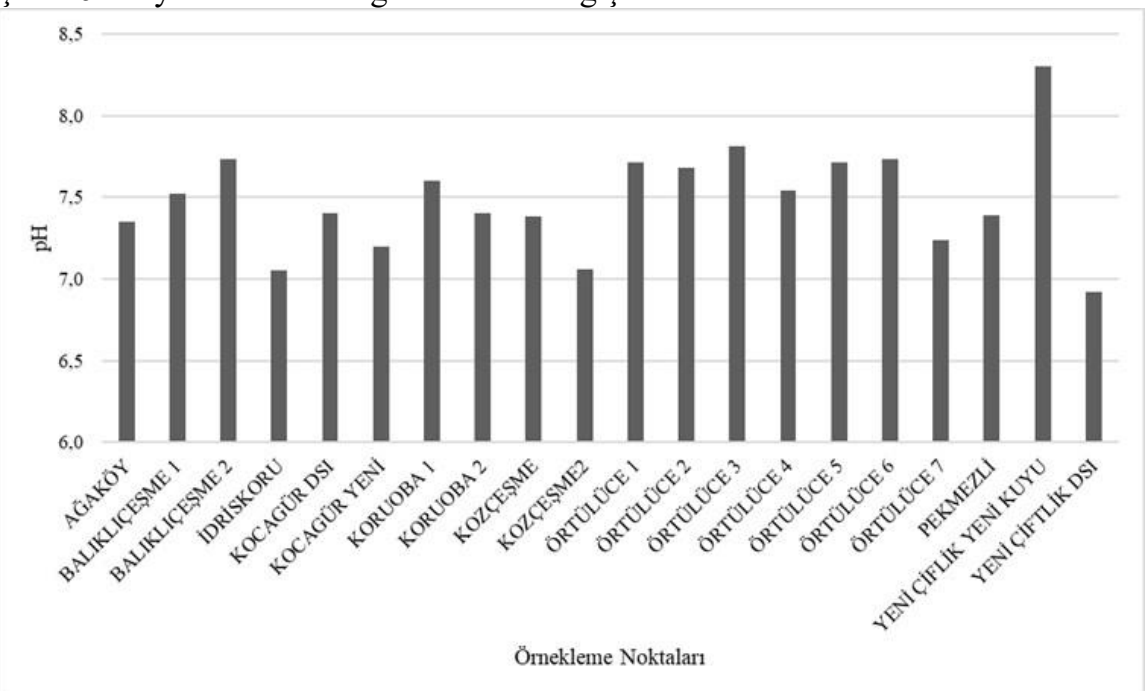

Şekil 7. Kuyuların $\mathrm{pH}$ değerlerindeki değişim. 


\section{Bor içeriğindeki değişim}

Bor elementi bitki gelişimi için gerekli bir element olsa da yüksek dozlarda toksisiteye neden olabilmektedir. Araştırma alanında yer alan kuyuların bor içeriklerindeki değişim Şekil 8'de gösterilmektedir. Su Kirliliği Kontrol Yönetmeliği'nin Kıtaiçi Yerüstü Su Kaynaklarının Sınıflarına Göre Kalite Kriterleri dikkate alındığında Yeni Çiftlik DSİ kuyusu 3,02 ppm ile 3. sınıfta yer almaktadır. Balıklıçeşme 1 (0,92 ppm), Balıklıçeşme 2 (1,83 ppm), İdriskoru (2,95 ppm), Kocagür DSI (1,91 ppm), Kocagür Yeni (1,05 ppm), Koruoba 1 (1,20 ppm), Kozçeşme (2,85 ppm), Kozçeşme 2 (1,53 ppm), Örtülüce 1 (1,36 ppm), Örtülüce 4 (1,91 ppm), Örtülüce 5 (1,75 ppm), Pekmezli (1,70 ppm) ve Yeni Çiftlik Yeni Kuyu (2,71 ppm) 2. sınıfta yer almaktadır.

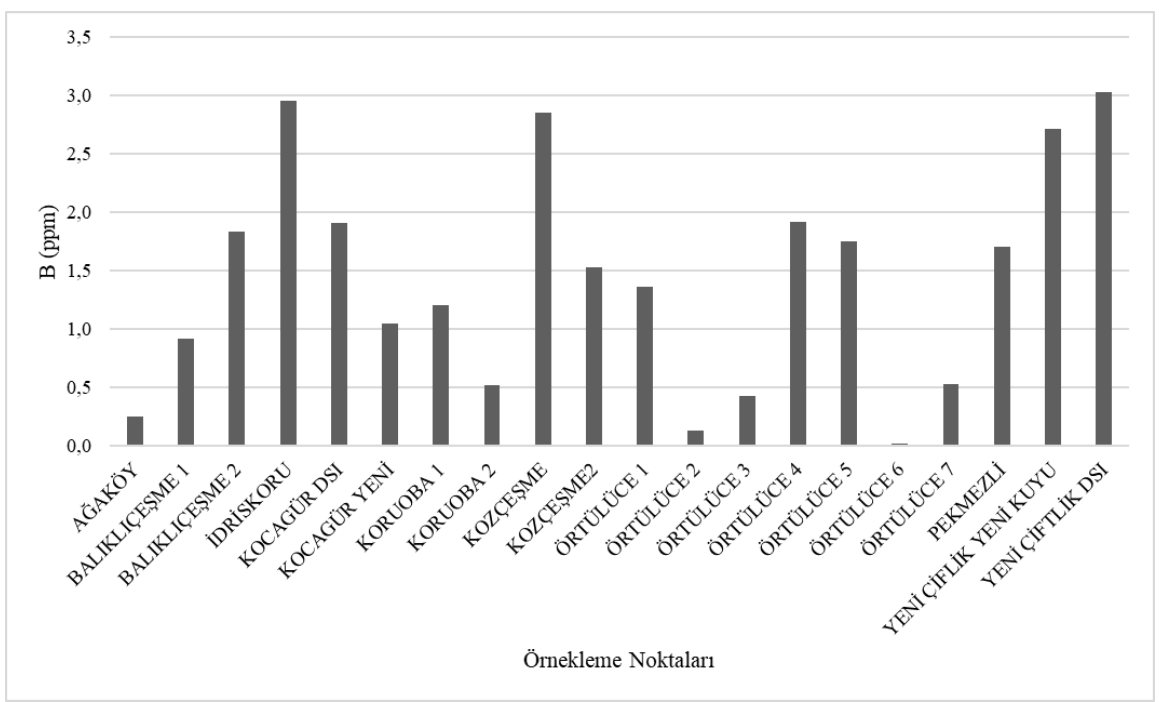

Şekil 8. Kuyuların Bor değerlerindeki değişim.

Çalışmadan elde edilen sonuçlar, çalışma alanına yakın bir bölge olan Bursa İnegöl Ovasında Taş ve Davarcı'nın (2017) yapmış oldukları çalışmada elde ettikleri değerlere göre daha yüksek olduğu belirlenmiştir. Söz konusu araştırmacıların çalışma yaptıkları bölgede çeltik üretimi yapılmayıp yaygın şekilde meyve üretimi yapılmaktadır. Bu nedenle kullanılan sulama suyu ve diğer girdilerin yeraltı sularını kirletmesi daha yavaş olmaktadır.

\section{Nitrat içeriğindeki değişim}

Son yıllarda yeraltı su kirliliğinde öne çıkan parametrelerin başında nitrat ve nitrit gelmektedir. Azot içeren sanayi atıkları, suni gübreler, bozulmaya uğramış organik maddeler nitrat ve nitritin kaynağını oluşturmaktadır. Araştırma alanındaki yeraltı su kuyularının nitrat içerikleri Su Kirliliği Kontrol Yönetmeliği' nin Kıtaiçi Yerüstü Su Kaynaklarının Sınıflarına Göre Kalite Kriterleri dikkate alındığında Örtülüce 7 (0 ppm), Yeni Çiftlik Yeni Kuyu (1,180 ppm) 1. sınıfta yer almaktadır. Kocagür DSİ (19,064 ppm), Koruoba 1 (13,690 ppm), Pekmezli (22,085 ppm) 3. sinıfa dahil olmuştur. Balıklıçeşme 1 (33,245 ppm), Balıklıçeşme 2 (46,142 ppm), Koruoba 2 (37,860 ppm), Kozçeşme 2 (37,870 ppm), Örtülüce 5 (46,285 ppm), Örtülüce $6(30,502 \mathrm{ppm}) 4$. sinıf olarak tespit edilmiştir. Ağaköy (82,350 ppm), İdriskoru (54,917 ppm), Kocagür Yeni (58,507 ppm), Kozçeşme (81,603 ppm), Örtülüce $1(63,200$ ppm), Örtülüce $2(71,846$ ppm), Örtülüce $3(57,431 \mathrm{ppm})$, Örtülüce 4 (100 ppm), Yeni Çiftlik DSİ (54,970 ppm) 5. sınıf yani zararlı ve sulamada kullanılması uygun olmayan sınıfta yer almıştır (Şekil 9).

Özdemir ve ark. (2004) kuyu sularında 243,61 mg/1; Yavuz ve ark. (1993) kuyu sularında 0,4546 ppm; Dağoğlu ve ark. (1995) kuyu ve kaynak sularında 50 ppm civarında nitrat kirliliği belirlemişlerdir. Çalışma alanından elde edilen değerler ile benzer çalışmalar kıyaslandığında, alanın büyük oranda nitrat kirliliği gösterdiği belirlenmiştir. Ayrıca, Ayers ve Westcot'un (1994) hayvan içme suları için önerdikleri nitrit üst limit (10 ppm) değerinin de çok üstünde olduğu belirlenmiştir. 


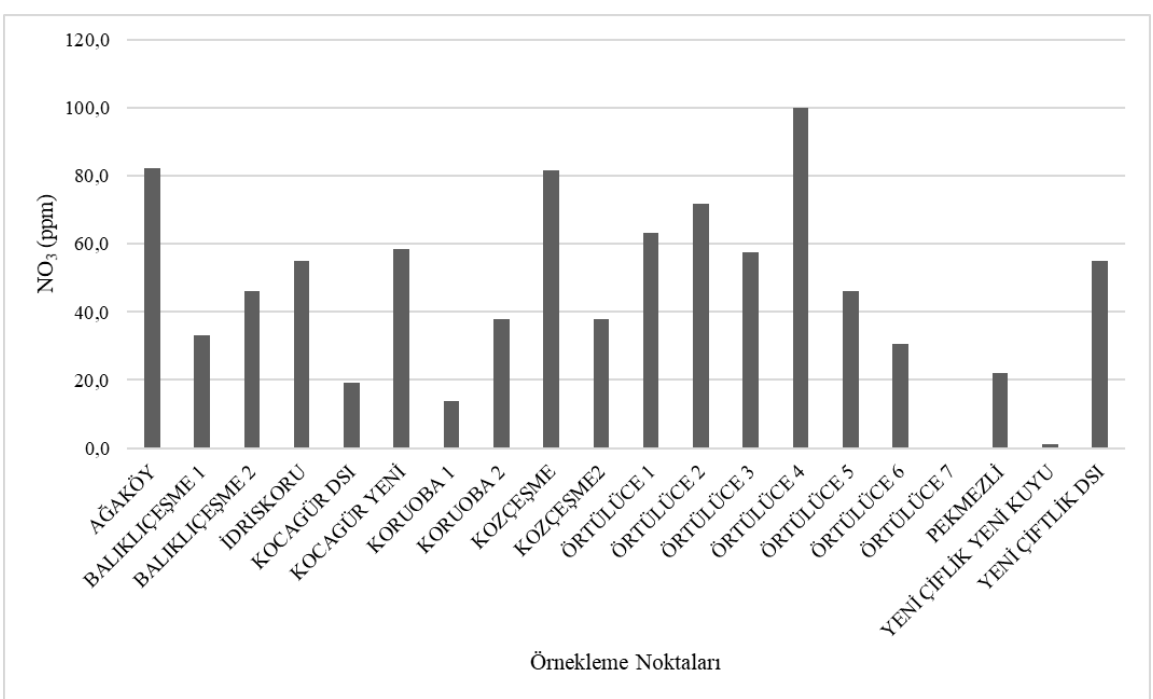

Şekil 9. Kuyuların Nitrat değerlerindeki değişim.

\section{Sonuç}

Üretimin en önemli girdisi olan sulama suyunun kalitesi söz konusu sürdürülebilir üretim için anahtar rol oynamaktadır. Yeraltı suyu kirlilik durumu açısından bakıldığında örnekleme yapılan kuyuların büyük bölümü EC, SAR ve pH değerleri açsından düşük risk göstermektedir.

Su Kalitesi Kontrol Yönetmenliği kriterlerine göre sınıflandırıldığında alanda büyük oranda nitrat kirliliği belirlenmiştir. Diğer bir ifadeyle Biga Ovası nitrat kirliliği bakımından şiddetli bir kirlilik göstermektedir. Yeraltı sularındaki nitrat kirliliğinin en önemli nedenlerinin başında yanlış gübreleme ve sulama uygulamaları gelmektedir. Sürdürülebilir tarımsal üretim için mutlak suretle hem gübre çeşitleri, miktarları, uygulama zamanları dikkatli bir şekilde belirlenmeli hem de sulama uygulamalarının ve etkin çalışan drenaj sistemlerinin kurulup işletilmesi gerekmektedir. Örneklenen yeraltı sularının günümüzdeki kaliteleri büyük oranda sulama suyu olarak kullanılabilir özellikte ancak Yeniçiftlik yeni kuyunun SAR değeri 11 olarak belirlenmiştir. Söz konusu kuyunun kullanılmas1 durumunda uzun vadede yeterli yıkamanın yapılmadığı koşullarda problemlere neden olacağı şeklinde değerlendirilmektedir. Sulama sularının bor içerikleri bakımından değerlendirildiğinde, bölgede mutlaka bora dayanıklı ve tercihen topraktan bor elementini kaldırabilen bitki türlerinin yetiştirilmesi önemlidir. Pamuk, kuşkonmaz, yonca, ayçiçeği, yerelması gibi bor dayanımı yüksek olan bitkilerin tercih edilmesi sürdürülebilir tarımsal üretim önemlidir. Zira, borlu toprakların ıslahı oldukça güç ve pahalı olması nedeniyle, bor içeriği yüksek suların uzun vadede kullanımlarında topraktaki birikimi izlenmeli ve gerekli tedbirler alınmalıdır.

Sonuç olarak, çalışma alanında kurak dönemlerde yeraltı sularının kullanımı artacağı için yeraltı suyu seviyesinde düşme meydana gelecektir. Aynı zamanda da yetersiz yer altı suyu beslemesi su kalitesini olumsuz etkileyecek diğer bir olumsuzluk olarak ortaya çıkmaktadır. Bu nedenle özellikle havzada izleme ve değerlendirme faaliyetlerinin dikkatli ve sürekli yapılması, başta bölge halkının yaşamı ve de sürdürülebilir tarımsal üretim için büyük önem arz etmektedir.

Not:Yüksek lisans tezinden üretilmiştir.

Teşekkür

Çanakkale Onsekiz Mart Üniversitesi Bilimsel Araştırma Projeleri Destekleme Komisyonu tarafindan FYL-2015464 nolu proje olarak desteklenmiştir. Yapılan destekten dolayı teşekkür ederiz.

\section{Kaynaklar}

AATTUT, 2019. Atıksu Arıtma Tesisleri Teknik Usuller Tebliği. Web Aresi: http://www.resmigazete.gov.tr/eskiler/2010/03/20100320-7.htm Erişim Tarihi: 01.08.2016 Anonim, 2016a. Web Adresi: http://www.biga.bel.tr/tr/yeri-ve-konumu-576. Erișim Tarihi: 08.04.2016. Anonim, 2016b. Biga Ticaret Borsası Stratejik Planı 2013-2016 Erişim Tarihi: 15.12.2015 
Angle, M.P., Baker, J., 2001. Groundwater Pollution Potential of Tuscarawas County, Ohio. Ohio Department of Natuaral Resources Division of Water Resources Section. Groundwater Pollution Potential Report No.52.

Ayers, R.S, Westcot, D.W., (1994) Water quality for agriculture. Irrigation and Drainage Paper, Food and Agriculture Organization of the United Nations, Rome, pp. 173.

Babiker, I.S., Mohamed, M.A.A., Hiyama, T., Kato, K., 2004. A GISbased DRASTIC Model for Assessing Aquifer Vulnerability in Kakamigahara Heights, Gifu Prefecture, Central Japan. Science of the Total Environment, 345: 127-140.

Bozdağ, A., 2017. Çumra (Konya) Ovasındakı Yeraltısularının Hidrojeokimyasal Özellikleri Ve Sulama Suyu Kalitesi. Mühendislik Bilimler ve Tasarım Dergisi, 5(3), $559-571$.

Dağoğlu, G, Bildik, A, Aksoy, A., 1995. Van yöresindeki sularda nitrat ve nitrit düzeyi. Firat Üniv Sağ Bil Derg; 9(2): 240-4

Demir, Y., Demir, A., D., 2019. Determination and Evaluation of Irrigation Water Quality in Areas Irrigated with Groundwater in the Southeast of Harran Plain. Turkish Journal of Agriculture - Food Science and Technology 7(11): 1894-1900, 2019.

Doğukan, H., Baran, Ş., Yorulmaz, H., Yenici, E., 2007. Çanakkale İli Çevre Durum Raporu. T.C. Çanakkale Valiliği İl Çevre ve Orman Müdürlüğü.

Ekinci, H., Çavuşgil, V., Özcan, H., Kavdır, Y., Yiğini, Y., Yüksel, O., 2008. Biga Ovası Toprak-Su Kaynakları Özellikleri ve Sorunları. 28 Ağustos 2008 Biga Değerleri Sempozyumu.

Katkat, A. V., Özgüven, N. Ç., 2000. Biga Yöresinde Sanayi Domatesi Yetiştirilen Toprakların ve Sulama Sularının Bazı Fiziksel ve Kimyasal Özellikleri. ÇEVKOR 9:34: 27-30.

Kavurmacı, M., Altaş, L., Kurmaç, Y., Işık, M., Elhatip, H., 2010. Tuz Gölü'nün Aksaray İli Yeraltı Sularına Etkisinin Coğrafi Bilgi Sistemi Kullanılarak Değerlendirilmesi. Çevkor Ekoloji 19, 77: 29-34

Nalbantçılar, M. T., 2011. Konya Kentsel Yeraltı Suyu Kirlilik Durumu Ve Kirlenebilirlik Potansiyeli. 1. Konya Kent Sempozyumu.

Osborn, N.I., Hardy, R.H., 1998. Statewide Groundwater Vulnerability Map of Oklahoma, Oklahoma Water Resources Board Technical Report 99-1.

Özdemir, M., Yavuz, H., İnce, S., 2004. Afyon bölgesi kuyu sularında nitrat ve nitrit düzeylerinin belirlenmesi. Ankara Üniv Vet Fak Derg 2004; 51: 25-8.

Taş, İ., Yıldırım, Y.E., Özkay, F., Aras, İ., 2013. Konya Ovasında Su Kalitesi ve Toprak Tuzluluğu. Ulusal KOP Bölgesel Kalkınma Sempozyumu. 14-16 Kasım 2013. Konya.

Taş, İ., Davarcı B., 2017. Bursa- İnegöl Ovası Yeraltı Su İçeriğinin On Yıllık Dönemdeki Değiş̧imi. Mediterranean Agricultural Sciences (2017) 30(2):143-149.

Yavuz, H., Kaya, S., Akar, F., 1993. Hayvanlarda içme suyu olarak kullanılan kuyu sularında nitrat ve nitrit düzeyleri. Ankara Üniv Vet Fak Derg; 40:16-22.

Yener, H., Ongun, A.R., 2017. Sarıgöl Ovası Yer Altı Su Kaynaklarının Sulama Amaçlı Kalitesinin Değerlendirilmesi. Türkiye Tarımsal Araştırmalar Dergisi, 4(3): 281 - 287.

Yıldıztekin, M., Tuna, A. L., 2011. Muğla Karabağlar Yöresi Kuyu Sularının Sulama Suyu Kalitesi Yönünden Araştırılması. Ege Üniv. Ziraat Fak. Derg., 48 (1): 1-10, 2011.

Zaporozec, A., Miller J.C., 2000. Yeraltı Suyu Kirliliği. International Hydrological Programme. Park Basım Evi Ltd, Verona, Wisconsin, USA. 